\title{
Momentos do Método Situacional no processo de ensino-aprendizagem dos Jogos Esportivos Coletivos: um aprofundamento conceitual
}

\section{Moments of the Situational Method in the teaching-learning process of Collective Sport Games: a conceptual deepening}

\begin{abstract}
Momentos del Método Situacional en el proceso de enseñanza-aprendizaje de los Juegos Deportivos Colectivos: una profundidad conceptual
\end{abstract}

\author{
Bruno Minuzzi Lanes ${ }^{I}$ João Francisco Magno Ribas II
}

\begin{abstract}
Resumo
O Método Situacional desponta como um recurso metodológico, visando superar os conhecimentos cartesianos que dissociam a técnica da tática no processo de ensino-aprendizagem dos Jogos Esportivos Coletivos. Na medida em que seu entendimento é fundamental para o campo da Pedagogia do Esporte, tanto no contexto científico, quanto na prática pedagógica, a presente pesquisa objetiva, a partir de um ensaio teórico-propositivo, aprofundar os conceitos inerentes aos momentos do Método Situacional. Com base nessa proposta, apresentam-se detalhamentos e explicações, com exemplos práticos desses conhecimentos para o processo de ensino-aprendizagem dos Jogos Esportivos Coletivos.
\end{abstract}

Palavras-chave: Pedagogia do Esporte; Métodos de Ensino; Esportes Coletivos; Tomada de Decisão

\begin{abstract}
The Situational Method emerges as a methodological resource, which aims to overcome the Cartesian knowledge that dissociates the technique from the tactic in the teaching-learning process of Collective Sports Games. As its understanding is fundamental to the field of Sport Pedagogy, both in the scientific context and in the pedagogical practice, the present research aims, from a propositional theoretical essay, to deepen the concepts inherent to the moments of the Situational Method. Based on this proposal, details and explanations are presented, with practical examples of this knowledge for the teaching-learning process of Collective Sports Games.
\end{abstract}

Keywords: Sport Pedagogy; Teaching methods; Collective sports; Decision-making

\footnotetext{
${ }^{\text {I }}$ Universidade Federal de Santa Maria - UFSM - Av. Roraima no 1000 Cidade Universitária Bairro - Camobi, Santa Maria - RS, $97105-900$ brunolanes10@hotmail.com

II Universidade Federal de Santa Maria - UFSM - ribasjfm@ hotmail.com
} 


\section{Resumen}

El Método Situacional surge como un recurso metodológico que pretende superar el conocimiento cartesiano que disocia la técnica de la táctica en el proceso de enseñanza-aprendizaje de los Juegos Deportivos Colectivos. Como su comprensión es fundamental para el campo de la Pedagogía Deportiva, tanto en el contexto científico como de la práctica pedagógica, la presente investigación tiene como objetivo, a partir de un ensayo teórico proposicional, profundizar los conceptos inherentes a los momentos del Método Situacional. A partir de esta propuesta se presentan detalles y explicaciones, con ejemplos prácticos de este conocimiento para el proceso de enseñanza-aprendizaje de los Juegos Deportivos Colectivos.

Palavras clave: Pedagogía Deportiva; Métodos de enseñanza; Deportes de equipo; Toma de decisiones

\section{Introdução}

O universo científico da Pedagogia do Esporte, que elucida questões de processos de ensinoaprendizagem, vem apresentado inúmeros estudos sobre as metodologias de ensino para os Jogos Esportivos Coletivos (JECs) (GRECO, 1998; GALATTI, 2006; PINHO, 2009; RIBAS, 2014; LANES, 2018; BITENCOURT, 2019; FAGUNDES, 2019). Os questionamentos e proposições acerca desse objeto de conhecimento têm salientado avanços pertinentes para professores e treinadores no campo educacional, desde a iniciação ao desempenho esportivo.

Em 1998, como parte desses estudos, Pablo Juan Greco sistematiza um modelo de ensino dos JECs, chamado de Método Situacional (MS), buscando superar os moldes tradicionais, que primam pelo ensino restrito ao componente técnico. Ao implementar novos conceitos o processo de ensino-aprendizagem dessas modalidades, como aspectos táticos, cognitivos, situações de jogo e estruturas funcionais, o autor organiza uma ferramenta pedagógica discutida no campo das Ciências dos Esportes até os dias atuais (LIMA; 2008; MATIAS, 2009; PINHO, 2009; RIBAS, 2014; LANES 2018).

De maneira geral, o MS proposto por Greco (1998) sistematiza o processo de ensino-aprendizagem dos JECs através de estruturas de atividades que simulam situações do jogo real. Essa característica, de acordo com Lanes (2018), permite ao jogador entrar em contato com os diversos elementos do jogo, com maior ou menor grau de complexidade. O modelo foi originalmente sistematizado no livro "Iniciação Esportiva Universal: metodologia da iniciação esportiva na escola e no clube" (GRECO, 1998). Nessa obra, o modelo constituiu-se em três momentos Inicial ou Linear, Posicional e Situacional.

Apesar de não tratar especificamente do Método Situacional, Ribas (2014) apresentou em sua obra, como proposta ao texto original, mais uma etapa na sua estrutura didático-pedagógica, chamada de Jogo Motriz. Nessa perspectiva, será considerado, no decorrer da pesquisa, o MS estruturado em quatro 
momentos de sistematização e serão apresentados os objetivos que devem ser desenvolvidos no processo de ensino-aprendizagem dos JECs, seja em apenas uma intervenção ou em um planejamento a longo prazo.

Dessa forma, os momentos são os seguintes: Linear ou Inicial, Posicional, Situacional e Jogo Motriz (GRECO, 1998; RIBAS, 2014). Para a materialização dos princípios orientados em cada momento do modelo, utilizam-se as estruturas funcionais, ferramentas que operacionalizam situações didáticas concretas. Greco (1998) corrobora nesse sentido ao afirmar sobre a importância de recorrer a formas de jogo, as denominadas estruturas funcionais, para que os momentos do Método Situacional (Linear, Posicional, Situacional e Jogo Motriz) proporcionem situações de aprendizagem.

De acordo com Greco (1998), a estrutura funcional é constituída de um ou mais jogadores, que realizam tarefas de ataque e de defesa. Nesse sistema, as atividades são organizadas de modo a considerar as características do jogo formal, porém com variações quanto ao número de participantes, espaço, tempo e regras (GRECO, 1998; COSTA; NASCIMENTO, 2004). Assim sendo, durante o processo de ensinoaprendizagem, as estruturas funcionais evidenciam-se como uma organização de tarefas motoras com diferenças quanto ao número de jogadores e quanto a complexidade de ações inerentes as características da lógica de funcionamento do jogo para promover situações de aprendizagem.

Como exemplo, para elucidação, pode-se pensar no Momento Situacional, no qual devem ser organizadas situações de jogo que condicionem os jogadores a um determinado desenvolvimento tático de leitura de jogo e tomada de decisão. Dessa forma, devem ser organizadas estruturas funcionais mais complexas, que apresentem um número maior de jogadores e de interações com companheiros e adversários, como, 2+1X2, 2X2+1, $2 \mathrm{X} 3^{1}$, dentre outras ordenações.

No entanto, constata-se que, desde sua proposição em 1998, o Método Situacional carece de um aprofundamento conceitual relativo a seus momentos de estruturação (LANES, 2018). O mesmo autor corrobora ao afirmar que, em uma breve pesquisa nos indexadores científicos nacionais, com publicações em língua portuguesa, foram encontrados 10 manuscritos (PÉREZ MORALES; GRECO, 2007; SILVA; GRECO, 2009; MATIAS; GRECO, 2011; LIMA; MARTINS COSTA; GRECO, 2011; RICCI et al, 2011; LIMA; MATIAS; GRECO, 2012; CASTRO et al, 2015; MENEZES; REIS; TOURINHO FILHO, 2015; MENEZES; REIS, 2017; LANES; RIBAS, 2018). Nesses textos, percebe-se ampla produção acadêmica sobre o MS em intervenções práticas; porém, existem fragilidades no tratamento teórico. Essa afirmação pode ser constatada na ausência de aprofundamento na estrutura didático-pedagógica (momentos do

${ }^{1}$ Nesse contexto lê-se + (companheiros) e $\mathbf{X}$ (adversários). 
método), linha epistemológica, bem como caracterização do desenvolvimento do processo de ensinoaprendizagem.

Sem o devido aprofundamento conceitual, essa percepção pode acarretar, por vezes, equívocos no entendimento acerca da estrutura didático-pedagógica, causando interferência durante as intervenções, como a não materialização de estruturas de atividades condizentes a cada momento do método, ou, até mesmo, situações de aprendizagem que não apresentem características relativas ao Método Situacional. Como afirma Demo (2009), a qualidade das intervenções está ligada justamente ao aprofundamento teórico existente acerca do objeto de conhecimento e, por isso, sua importância.

Esse fenômeno instiga a problemática deste ensaio que objetiva aprofundar os conceitos inerentes aos momentos do Método Situacional. Com base nesse avanço conceitual, serão apresentados também detalhamentos e explicações, com exemplos práticos, dos conhecimentos para o processo de ensinoaprendizagem dos JECs. Esse estudo originou-se como parte da dissertação de mestrado apresentada junto à Universidade Federal de Santa Maria - UFSM. Além disso, justifica-se na medida em quem, é essencial um entendimento aprofundado para apropriar-se, de maneira clara e coerente, de um objeto de conhecimento, nesse caso o MS.

Essa investigação busca, na organização de um ensaio teórico propositivo, melhor compreender e aprofundar os elementos inerentes à problemática da pesquisa. De acordo com Gil (2008), quando a medida se utiliza análise teórica de conceitos difundidos em estudos bibliográficos, é facilitada a comprovação de conhecimentos que carecem de um maior aprofundamento. A pesquisa teórica monta e desvenda quadros teóricos de referência, na procura por uma reconstrução a partir de um estudo apurado de outras teorias (DEMO, 1985; DEMO, 2009). Nessa perspectiva, esse tipo de pesquisa auxilia no burilamento conceitual, domínio de alternativas explicativas e capacidade de descrição discursiva e analítica (DEMO, 2006). Na mesma linha de compreensão, o caráter propositivo tem como intuito oferecer argumentos e conceitos suficientes para demonstrar a importância daquilo que está sendo defendido no texto (SALVADOR, 1986).

\section{Resultados e discussão}

Nas descrições realizadas até o momento, foram introduzidos os conceitos inerentes ao MS, bem como, os elementos conceituais que o constituem e embasam sua materialidade no decorrer do planejamento e organização de um processo de ensino-aprendizagem de JECs. Neste estudo, entende-se que os momentos Linear, Posicional, Situacional e Jogo Motriz são responsáveis por indicar e estruturar os 
princípios metodológicos a serem considerados pelo professor-treinador durante a aula, seção de treinamento e, ao longo prazo, durante o processo de ensino-aprendizagem. Nessa organização, as estruturas funcionais atuam como as situações de aprendizagem que viabilizam arquitetar os condicionantes necessários para o desenvolvimento direcionado das capacidades, como leitura de jogo e tomada de decisão, e habilidades a serem aprimoradas.

Assim, pode-se dizer que os momentos do MS arranjam um "passo a passo" para orientar e indicar o caminho a ser seguido pelo professor-treinador. Dessa forma, oportunizam o planejamento e a sistematização do processo de ensino-aprendizagem, bem como as formas para se atingir o êxito nesse sistema. Com base nas afirmações supracitadas, sucede-se, no decorrer do texto, o aprofundamento conceitual dos momentos do MS, o detalhamento teórico inerente a esses elementos e, a apresentação de alguns exemplos, que facilitam a visualização desses conceitos em uma situação prática.

Momento Linear ou Inicial: de acordo com Greco (1998) o objetivo dessa fase está direcionado à aquisição dos conhecimentos táticos de forma mais simplificada e ao desenvolvimento/aperfeiçoamento da mecânica das ações técnicas. Durante esse momento o professor-treinador deve oportunizar estruturas de atividades que operacionalizem a inter-relação da técnica e da tática através de situações de jogo pouco complexas. Com isso, o profissional condiciona no jogador o desenvolvimento de esquemas mentais que o auxiliam na execução técnica eficaz para a solução dos problemas táticos (GRECO, 1998). Samulski (2002) corrobora ao detalhar as tarefas específicas da capacidade tática dos esportes, afirmando que um prérequisito para qualquer ação é a formação de uma imagem mental, a qual indicará uma atualização e sentido sobre o objetivo do próprio movimento.

A partir da intepretação do conceito acima, constata-se que o Momento Inicial ou Linear apresenta maior ênfase no desenvolvimento de uma ação técnica específica (ação que se objetiva desenvolver/aperfeiçoar). Não significa que os aspectos táticos não estão inseridos, pois nos JECs não é possível dissociar a técnica da tática. Por outro lado, a execução de um gesto técnico ocorre a partir de uma necessidade apresentada pelo jogo (COSTA; NASCIMENTO, 2004; SOARES; GRECO, 2010).

Dessa forma, esse momento do MS, considera os elementos táticos, de modo a dar sentido aos requisitos técnicos e fornecer ao jogador uma compreensão do motivo do desenvolvimento/aperfeiçoamento de determinada ação. Segundo Greco (2017) nessa fase, os princípios táticos não condicionam o comportamento do jogador a ler determinada ação e a tomar decisões. O mesmo autor salienta ainda que esses aspectos são indicados como estímulos, permitindo, a um dado momento, compreender as demandas do jogo a partir da sua lógica de funcionamento. 
A critério de exemplo, no Voleibol, no momento em que o jogador tem o objetivo de desenvolver/aperfeiçoar sua "ação de toque", em uma estrutura de atividade que indica a troca de toques altos com outro jogador, está realizando o exercício com um determinado sentido. Essa finalidade apresenta as demandas necessárias para execução da ação motora. Além disso, elementos táticos inerentes a leitura de jogo estão inseridos, como percepção da trajetória da bola, do outro jogador, posição de interceptação da bola no espaço. No entanto, como evidenciado, esses elementos não condicionam o comportamento e a ação do jogador a uma determinada leitura de jogo e tomada de decisão, pois a situação de aprendizagem enfatiza e induz o aprimoramento técnico.

Esse entendimento vai ao encontro de Greco (1998) ao afirmar que o Momento Inicial ou Linear promove no jogador a formação de esquemas mentais para solucionar as situações problemas, enquanto gera um refinamento das ações técnicas. Dessa forma, quando à o jogador compreende o "porquê" desenvolver/aperfeiçoar determinada ação, forma um plano mental específico norteador do processo de “como” realizar a ação, quando for necessária em uma situação de jogo.

O desenvolvimento técnico é fundamental no processo de ensino-aprendizagem, visto que os jogadores direcionam sua percepção aos elementos relativos à capacidade tática, deixando à de se preocupar com a execução das ações técnicas (OLIVEIRA; RIBAS; GOMES-DA-SILVA, 2018). Dessa forma, a realização de uma técnica é concretizada quando o jogador consegue atingir uma complexa combinação de mecanismos mentais e motores (GRECO, 1998). Por isso, o completo domínio técnico e a formação de esquemas mentais específicos, trabalhados no decorrer do momento Linear ou Inicial, potencializam o desenvolvimento dos processos de leitura de jogo e tomada de decisão enfatizados nos momentos seguintes.

Momento Posicional: esse momento de acordo com Greco (1998), almeja desenvolver nos jogadores a precisão das ações técnicas e táticas a partir dos elementos inerentes ao espaço e tempo que compõem o jogo. Esse componente tem o objetivo de coordenar o desempenho na tarefa a partir de distâncias, deslocamentos, forças e direções, ou seja, princípios espaço-temporais relativos à bola, aos outros jogadores e ao espaço de jogo (campo, quadra). Dessa forma, o momento Posicional visa ao aprimoramento das ações de jogo, a partir dos processos perceptivos, relativos aos segmentos espaciais e temporais (GRECO, 1998).

Com base na análise conceitual, entende-se que a ênfase do Momento Posicional se mantém nos aspectos predominantemente técnicos, assim como no Momento Linear ou Inicial. Contudo, na etapa anterior (Momento Linear ou Inicial), o jogador desenvolve/aperfeiçoa o "como" executar sua ação, de modo a formar um mapa mental amplo que considera todas as possibilidades de o "porquê" e de "quando" concretizar a ação técnica no jogo (LANES, 2018). Na perspectiva Posicional, portanto, o jogador passa a 
otimizar os esquemas mentais desenvolvidos previamente, com base nos sinais reconhecidos, identificados e decodificados inerentes aos componentes espaço temporais (espaço de jogo, bola, jogadores e espaços e posições específicas ocupadas durante o jogo).

Para corroborar a descrição, Mogadouro (2008) afirma que o aprimoramento das capacidades técnicas e táticas depende das configurações espaço-temporais pois esse princípio também apresenta um grau de imprevisibilidade no jogo. Dessa forma, norteia a execução da ação técnica, ou seja, deixa de apenas indicar as inúmeras possibilidades de realização e introduz uma situação específica de jogo. Assim, no Momento Posicional, ocorre, com menor grau de complexidade, a integração técnico-tática do processo de ensino-aprendizagem. Esse fato ocorre, devido ao Momento Posicional apresentar estruturas de atividades menos complexas quanto às ações e ao número de jogadores do que no momento Situacional.

No futsal por exemplo, é fundamental a clareza do jogador quanto à distância entre um ponto e outro da quadra, bem como a direção de execução d passe, pois essa ação motora é essencial para alcançar êxito no jogo. Se a força e direção empregadas na bola não forem corretas, as chances de o passe ser interceptado por um jogador adversário aumentam conforme a precisão diminui. Portanto, o ato de executar a ação motora é fundamental, no entanto, sem considerar esses princípios, não é garantia de eficácia no decorrer do jogo (RIBAS, 2014; MARQUES FILHO, 2017).

Isso se torna perceptível ao se observar as constantes rotações e trocas de posições dos jogadores, durante o jogo, para fornecer maiores possibilidades de execução técnica do passe. Também como exemplo no Voleibol, sabe-se que cada posição em quadra, espaços, tempo de ação e atuação e trajetórias se modificam, influenciando no processo de ensino-aprendizagem e exigindo um trabalho mais específico se comparado ao Momento Linear ou Inicial (GRECO, 1998).

Durante o momento Posicional, os elementos espaço-temporais começam a ser considerados de maneira mais específica. Se anteriormente o jogador compreendia que determinada ação poderia ser utilizada na resolução de uma situação problema, nessa etapa, precisa compreender que a ação deverá ser orientada em uma situação concreta de menor complexidade. Assim, acarretará otimização de suas estruturas mentais, formadas antecipadamente, e aperfeiçoamento da mecânica da ação técnica com base nas distâncias, posicionamento, espaço a ocupar em quadra, força a empregar na bola, esquemas de jogo, dentre outros procedimentos.

Por fim, constata-se que mesmo enfatizado o desenvolvimento/aperfeiçoamento técnico, os aspectos relativos à capacidade tática tornam-se instrumentalizados quando o espaço de jogo apresenta um caráter mais formal. Essa peculiaridade do Momento Posicional evidencia os aspectos técnicos e táticos integrados 
e outras demandas fundamentais do jogo para o desenvolvimento do processo de ensino-aprendizagem dos JECs

Momento Situacional: de acordo com Greco (1998) a etapa situacional do processo de ensinoaprendizagem é caracterizada pelo refinamento e domínio dos aspectos técnico-táticos desenvolvidos nos momentos Linear e Posicional. Nesse momento devem ser oportunizadas situações de jogo semiestruturadas para colocar o jogador em contato com as características mais próximas a do jogo formal (GRECO, 1998; CORRÊA; SILVA; PAROLI, 2004). Dessa forma, os elementos relativos às capacidades táticas de leitura de jogo e tomada de decisão são propostos e instrumentalizados de forma intencional pelo professor-treinador. O Momento Situacional tem por objetivo desenvolver variações técnicas para solucionar as distintas situações táticas do jogo, considerando as muitas intepretações do contexto (GRECO, 1998).

Constata-se que, no decorrer desse momento existe uma intencionalidade que permite induzir no jogador ao desenvolvimento dos processos de leitura de jogo e tomada de decisão, com base nos aspectos inerentes à lógica de funcionamento do jogo. Nessa etapa, oportunizam-se estruturas de atividades predefinidas a determinados cenários que condicionarão o jogador a executar determinada tomada de decisão para solucionar a tarefa-problema. É importante salientar que nos outros momentos do MS essa sistematização também ocorre, porém com menor ênfase nos processos de leitura de jogo e tomada de decisão se comparados Momento Situacional (LANES, 2018).

Nessa situação, o jogador deve interpretar as informações emitidas pelos componentes do contexto do jogo e filtrar, dentre as possibilidades de ação, qual a tomada de decisão (ação motora) resolve a tarefa. Greco (2006) e Schmidt e Wrisberg (2001) advogam que a seleção da resposta (decisão) depende inicialmente da percepção e interpretação do estímulo, para que a seguir a tomada de decisão possa ser programada.

Portanto, no decorrer dessa etapa, deve-se estruturar exercícios padronizados a um determinado comportamento tático, condicionando a tomada de decisão do jogador para que sua ação e atuação no jogo sejam capazes de resolver a situação-problema (GRECO, 1998). O mesmo autor enfatiza que, ao desenvolver os processos de leitura de jogo e tomada de decisão, consequentemente, está se interrelacionando os aspectos técnicos, táticos, cognitivos, físicos e psíquicos. Nessa perspectiva, de acordo com Lanes (2018), para a resolução de um problema esportivo, é necessário perceber e interpretar bem o contexto do jogo, tomar a decisão correta, dominar a execução das ações técnicas relativas a essa tomada de decisão, bem como lidar com os estresses e situações psíquicas. 
No Momento Situacional, são organizadas situações de jogo que induzem o jogador a interpretar e decidir uma determinada tomada de decisão, que originará melhor execução técnica para resolver tal problema. Ribas (2014) e Lanes e Ribas (2018) salientam que nessas estruturas de atividades devem ser contemplados elementos da lógica de funcionamento dos JECs com menor ou maior grau de complexidade, pois os processos de leitura de jogo e tomada de decisão estão condicionados a esses princípios.

Como exemplo, pode-se pensar no arremesso no Basquetebol, tendo por objetivo o aperfeiçoamento do arremesso de três pontos. Durante o momento Situacional, tal objetivo deverá estar presente nas estruturas de atividades de modo que condicione o comportamento do jogador. Para isso, em um caráter prático, pode-se organizar uma defesa que proteja a área restrita e dê maior liberdade ao jogador no arremesso de longa distância. Essa estrutura induzirá seu comportamento a executar determinada ação, pois oferecerá estímulos ambientais que dificultam a infiltração. Tais condicionantes tornam o arremesso de dois pontos desfavorável e facilitam o arremesso de perímetro (três pontos).

Vale salientar aqui, como já descrito anteriormente, que a automatização da ação técnica, nesse caso do arremesso, é fundamental para o jogador perceber e processar as informações emitidas pelo contexto do jogo para tomar a decisão que lhe foi induzida, uma vez que não precisará preocupar-se efetivamente em executar a ação motora (LANES, 2018). Da mesma forma, por vezes os jogadores interpretam de modo inteligente o contexto do jogo, tomam a decisão considerada mais correta, porém, ao executar a ação cometem erros. Nesse sentido, visualiza-se que os componentes táticos e técnicos são indissociáveis.

Jogo Motriz: esse momento foi indicado por Ribas (2014) como acréscimo ao MS. O autor identificou a importância de sistematizar jogos adaptados durante o processo de ensino-aprendizagem dos JECs. Durante essa etapa deve-se manter o foco no desenvolvimento dos processos de leitura de jogo e tomada de decisão. A estruturação de um jogo adaptado na sistematização do MS facilita a transposição das situações didáticas de exercício para o jogo, pois propicia uma estrutura funcional com um sistema de pontuação que contempla semelhanças mais concretas ao jogo formal (RIBAS, 2014).

Esse elemento competitivo, relativo ao sistema de pontuação, torna-se considerável, pois algumas capacidades psíquicas inerentes ao jogo são ativadas. Consequentemente, coloca o jogador à "prova" em situações de pressão, semelhantes ao que deverá acontecer no ambiente de jogo institucionalizado. Segundo Lanes (2018), realizar determinadas ações técnico-táticas em um ambiente de jogo controlado é completamente diferente do universo competitivo, pois existem inúmeras situações desfavoráveis evidenciadas nessa atmosfera de disputa formal.

Por fim, o Jogo Motriz varia desde jogos reduzidos até a instrumentalização de um jogo formal com regras adaptadas. O que fundamenta sua sistematização são as adaptações intencionais condicionadas às 
finalidades no processo de ensino-aprendizagem dos JECs. Pode-se visualizar exemplos já conhecidos, de Jogo Motriz. O "manchetão" no Voleibol, o jogo dos dez passes no Handebol e Basquetebol, jogo dividido em zonas da quadra no Futsal, todos reduzidos e/ou adaptados apresentando um determinado objetivo condicionante do comportamento do jogador.

Com base nas afirmações citadas anteriormente no decorrer do texto, constata-se que os momentos do MS possuem conceitos significativos para a sistematização do processo de ensino-aprendizagem dos JECs. A estruturação desse modelo de ensino alicerçado em uma sequência metodológica, proporciona a elaboração de situações de aprendizagem que vão sendo construídas umas sob as outras, na medida em que os objetivos, para com a aprendizagem dos jogadores ganham complexidade e evidenciam os conhecimentos inerentes ao jogo (GRECO, 1998; LANES; RIBAS, 2018). O detalhamento conceitual apresentado colabora com os professores-treinadores no planejamento e materialização de suas ações pedagógicas fundamentadas nos princípios do MS.

\section{Considerações finais}

Essa investigação objetivou aprofundar os conceitos inerentes aos momentos do Método Situacional. Além disso, com base nesse avanço conceitual, a pesquisa dispôs-se a realizar detalhamentos e explicações inerentes a estrutura metodológica desse modelo. Nesse aspecto, o processo de ensinoaprendizagem dos JECs ganhou evidencia como um pressuposto que concretiza na "prática" tais conhecimentos teóricos salientados.

Esse estudo constituiu-se metodologicamente ao reestruturar conceitos a partir de outros já estabelecidos cientificamente. A priori, salientou-se uma contextualização geral sobre o MS, na qual evidenciaram-se suas bases teóricas, características, princípios destacados e conhecimentos e fundamentos. A partir disso, os momentos do MS foram evidenciados e caracterizados segundo a produção já existente, o que possibilitou o aprofundamento teórico. Com base nesse delineamento, foi apresentado um detalhamento dos conhecimentos inerentes à estrutura metodológica do modelo exemplificando-a para melhor compreensão e orientação no processo de ensino-aprendizagem.

Dessa forma, o detalhamento conceitual realizado no decorrer da pesquisa poderá colaborar com profissionais interessados em apropriar-se de conhecimentos inerentes ao Modelo Situacional e voltados às dificuldades para conhecer e operacionalizar esses. Nessa perspectiva, a investigação caracteriza-se como material de suporte para eventuais estudos posteriores no campo da Pedagogia do Esporte, além de auxiliar a instrumentalização desses elementos no processo de ensino-aprendizagem dos JECs. Assim, o 
aprofundamento conceitual e o detalhamento teórico realizado fornecem embasamento para pesquisadores, professores e treinadores na compreensão e sistematização dos conhecimentos do MS.

\section{Referências}

BITENCOURT, Willian Daniel. O ensino do futsal: uma proposta a luz da Praxiologia Motriz e dos Jogos Condicionados. 2019. 90 f. Dissertação (Mestrado em Educação Física) -Universidade Federal de Santa Maria, Santa Maria, 2019.

CASTRO, Henrique de Oliveira; PEREZ MORALES, Juan Carlos; ABURACHID, Layla Maria Campos;

GRECO, Juan Pablo. Teste de conhecimento tático processual 3x3 com os pés: alternativa para a orientação esportiva. Revista Brasileira de Educação Física e Esporte, São Paulo, SP, v. 29, n. 4, p. 621-629, 2015.

CORRÊA, Umberto Cesar; SILVA, António Sabino da; PAROLI, Rejane. Efeitos de diferentes métodos de ensino na aprendizagem do futebol de salão. Motriz, Rio Claro, v.10, n.2, p.79-88, mai./ago. 2004.

COSTA, Luciana Cristina Arantes da; NASCIMENTO Juarez Vieira do. O ensino da técnica e da tática: novas abordagens metodológicas, Revista da Educação Física/UEM, Maringá, v. 15, n. 2, p. 49-56, 2004.

DEMO, Pedro. Introdução à metodologia da ciência. 2aed. São Paulo: Atlas. 1985.

DEMO, Pedro. Pesquisa e construção de conhecimento: metodologia científica no caminho de Habermas: Tempo Brasileiro, 2009.

DEMO, Pedro. Pesquisa: princípio científico e educativo: Cortez, 2006.

FAGUNDES, Felipe Menezes. O modelo Teaching Games for Understanding e a Praxiologia Motriz: Sistematização do ensino para a compreensão da lógica interna do Voleibol. 2019. 135 f. Dissertação (Mestrado em Educação Física) -Universidade Federal de Santa Maria, Santa Maria, 2019.

GALATTI, Larissa Rafaela. Pedagogia do esporte: o livro didático como um mediador no processo de ensino e aprendizagem de jogos esportivos coletivos. 2006. 139f. Dissertação (Mestrado em Educação Física) - Faculdade de Educação Física, Universidade Estadual de Campinas, Campinas, 2006.

GIL, Antônio Carlos. Métodos e Técnicas de Pesquisa Social. 6. ed. São Paulo: Atlas, 2008.

GRECO, Pablo Juan. Banca de qualificação de Mestrado. [jun. 2017]. Santa Maria: UFSM, 2017. Comunicação proferida como ocasião de banca de qualificação de mestrado em Educação Física da Universidade Federal de Santa Maria.

GRECO, Pablo Juan. Conhecimento tático-técnico: modelo pendular do comportamento e da ação nos esportes coletivos. Revista Brasileira de Psicologia do Esporte e do Exercício, v.1, p.107-129. 2006.

GRECO, Pablo Juan. Iniciação Esportiva Universal: metodologia da iniciação esportiva na escola e no clube. Belo Horizonte: UFMG, 1998. 
LANES, Bruno Minuzzi. Ensino-aprendizagem-treinamento do Voleibol: proposições a partir da Praxiologia Motriz e o Método Situacional. 2018. 169 f. Dissertação (Mestrado em Educação Física) Universidade Federal de Santa Maria, Santa Maria, 2018.

LANES, Bruno Minuzzi; RIBAS, João Francisco Magno. As Interações Motrizes do Voleibol e o Método Situacional: reflexões para o processo de ensino-aprendizagem. Revista Pensar a Prática, Goiânia, v. 21, n. 1, jan./mar. 2018.

LIMA, Cláudio Olivio Vilela. Desenvolvimento do Conhecimento Tático Declarativo e Processual no Processo de Ensino-Aprendizagem-Treinamento do Voleibol Escolar. 2008. 166f. Dissertação (Mestrado) - Universidade Federal de Minas Gerais, Belo Horizonte, 2008.

LIMA, Cláudio Olivio Vilela; MARTINS COSTA, Hugo Cesar; GRECO, Pablo Juan. Relação entre o processo de ensino-aprendizagem-treinamento e o desenvolvimento do conhecimento tático no voleibol. Revista Brasileira de Educação Física e Esporte, São Paulo, SP, v.25, n.2, p.251-261, 2011.

LIMA, Cláudio Olivio Vilela; MATIAS, Cristiano Julio Alves Silva; GRECO, Pablo Juan. O Conhecimento tático produto de métodos de ensino combinados e aplicados em sequências inversas no voleibol. Revista Brasileira de Educação Física e Esporte, São Paulo, SP, v. 26, n. 1, p. 129-147, 2012.

MARQUES FILHO, Cesar Vieira. A estruturação do futebol e seus elementos pedagógicos: uma visão a partir da Praxiologia Motriz. 2017. 78 f. Dissertação (Mestrado em Educação Física) - Universidade Federal de Santa Maria, 2017.

MATIAS, Cristiano Julio Alves da Silva. O Conhecimento Tático Declarativo e a distribuição de jogo do levantador de Voleibol: da formação ao alto nível. 2009. 260 f. Dissertação (Mestrado em Educação Física) - Universidade Federal de Minas Gerais, Belo Horizonte, 2009.

MATIAS, Cristiano Julio Alves Silva; GRECO, Pablo Juan. Conhecimento tático-estratégico dos levantadores brasileiros campeões de voleibol: da formação ao alto nível. Revista Brasileira de Educação Física e Esporte, São Paulo, SP, v.25, n.3, p.513-35, jul./set. 2011.

MENEZES, Rafael Pombo; REIS, Heloisa Helena Baldy. O jogo defensivo diante de diferentes sistemas ofensivos no handebol: análise do cenário técnico-tático e reflexões sobre o ensino. Revista Brasileira de Ciências do Esporte, Brasília, DF, v. 39, n. 2, p. 168-175, 2017.

MENEZES, Rafael Pombo; REIS, Heloisa Helena Baldy; TOURINHO FILHO, Hugo. Ensinoaprendizagem-treinamento dos elementos técnico-táticos defensivos individuais do Handebol nas categorias infantil, cadete e juvenil. Movimento, Porto Alegre, RS, v. 21, n. 1, p. 261-273, jan./mar. 2015.

MOGADOURO, Ângela. Formação dos Jogos Desportivos Coletivos. 2012. 57 f. Dissertação (Mestrado em Educação Física) - Faculdade de Desporto da Universidade do Porto, 2012.

OLIVEIRA, Raquel Valente de; RIBAS, João Francisco Magno; GOMES-DA-SILVA, Pierre Normando. Relação entre o Praxema e as Interações Motrizes: implicações nos processos de Leitura de Jogo e Tomada de Decisão nos Jogos Esportivos Coletivos. Pensar a Prática, v. 21, n.2. 2018.

PEREZ MORALES, Juan Carlos; GRECO, Juan Pablo. A influência de diferentes metodologias de ensinoaprendizagem-treinamento no basquetebol sobre o nível de conhecimento tático processual. Revista Brasileira de Educação Física e Esporte, São Paulo, SP, v. 21, n. 4, p. 291-299, 2007. 
PINHO, Silvia Teixeira de. Método Situacional e sua influência no conhecimento tático processual de escolares. 100 f. Dissertação (Mestrado em Educação Física) Universidade Federal de Pelotas, Pelotas, 2009.

RIBAS, João Francisco Magno (Org). Praxiologia Motriz e Voleibol: Elementos para o Trabalho Pedagógico. Ijuí: Unijuí, 2014.

RICCI, Giuliano Salera et al. Avaliação da aprendizagem do handebol por jovens entre 11 e 14 anos a partir do Método Situacional. Pensar a Prática, Goiânia, GO, v. 14, n. 1, p. 1-18, jan./abr. 2011.

SALVADOR, Angelo Domingos. Métodos e Técnicas de Pesquisa Bibliográfica. Porto Alegre: Sulina, 1986.

SAMULSKI, Dietmar. Psicologia do Esporte: Manual para a Educação Física, Psicologia e Fisioterapia. São Paulo: Manole. 2002.

SCHMIDT, Richard A.; WRISBERG, Craig A. Aprendizagem e performance motora: uma abordagem da aprendizagem voltada para o problema. Porto Alegre: Artmed, 2001.

SILVA, Marcelo Vilhena; GRECO, Pablo Juan. A influência dos métodos de ensino-aprendizagemtreinamento no desenvolvimento da inteligência e criatividade tática em atletas de futsal. Revista Brasileira de Educação Física e Esporte, São Paulo, SP, v. 23, n. 3, p. 297-307, 2009.

SOARES, Vinícius de Oliveira Viana; GRECO, Pablo Juan. A análise técnica-tática nos Esporte Coletivos: "por que, "o quê", e "como". Revista Mackenzie de Educação Física e Esporte - V. 9, N. 2, 3-11. 2010.

\section{Como citar este artigo}

LANES, B. M.; RIBAS, J. F. M. Momentos do Método Situacional no processo de ensinoaprendizagem dos Jogos Esportivos Coletivos: um aprofundamento conceitual. Revista Kinesis, Santa Maria, v. 39, p.01-13, 2021.

* Este trabalho contou com incentivo e apoio financeiro da CAPES/CNPq. 